\section{Increasing Organic Fertilizer and Decreasing Drip Chemical Fertilizer for Two Consecutive Years Improved the Fruit Quality of 'Summer Black' Grapes in Arid Areas}

\author{
Fengyun Zhao, Yu Jiang, Xiufeng He, Huaifeng Liu, and Kun Yu \\ Department of Horticulture, Agricultural College, Shihezi University, \\ Shihezi 832003, Xinjiang, PR China; Key Laboratory of Special Fruits and \\ Vegetables Cultivation Physiology and Germplasm Resources Utilization of \\ Xinjiang Production and Construction Crops, Shihezi 832003, Xinjiang, PR \\ China
}

Additional index words. chemical fertilizer, grape, growth, organic fertilizer, quality

\begin{abstract}
The use of water-soluble chemical fertilizers for years under drip irrigation conditions results in soil compaction, fertility decline, and fruit quality decrease in arid areas. Currently, little research has been reported regarding the effects of increasing organic fertilizer and reducing drip chemical fertilizer on the growth of grape plants under different conditions in arid areas. In this study, five different treatments were conducted. Compared with no fertilizer for 3 consecutive years (CK) and single fertilizer for 3 consecutive years (T0), organic fertilizer plus 1 year of reducing drip chemical fertilizer (T1), organic fertilizer plus 2 years of reducing drip chemical fertilizer (T2), and organic fertilizer plus 3 years of reducing drip chemical fertilizer (T3) improved the soil pH, electrical conductivity (EC) values, and soil organic matter content to different degrees during early growth stages (15 days after anthesis) and mature stages (75 days after anthesis). The available $N, P$, and $K$ contents in the $T 1$ and $T 2$ treatments increased significantly. With the $T 2$ treatment, the longitudinal and transverse diameters of the 'Summer Black' grapes were the largest during the two fruit expansion periods. The anthocyanin content of grape peel with the $T 2$ treatment was $22.0 \%$ higher than that with the $T 0$ treatment. The soluble solids, sugar-acid ratio, various sugar contents, vitamin $C$, and total phenol of the fruit increased significantly with the $T 2$ treatment, indicating that the $\mathbf{T} 2$ treatment was best for promoting grape growth and fruit quality and that the T3 treatment was the second best.
\end{abstract}

Grape (Vitis vinifera L.) has been grown for thousands of years. In 2016, the total planting area of grapes in China was $\approx 809,000 \mathrm{hm}^{2}$ (Huang, 2017), of which Xinjiang accounted for $18.4 \%$ (or $149,000 \mathrm{hm}^{2}$ ). Since 1994, watersaving agriculture in the arid regions of Xin-

Received for publication 22 Aug. 2019. Accepted for publication 23 Oct. 2019.

Published online 7 January 2020.

This work was jointly supported by the National Key R\&D Program Projects (2018YFD1000200), the Natural Science Foundation of China (31760550), Corps major scientific and technological project plan (2016AA002), Major Science and Technology Research Project of Shihezi University (Gxjs2015-zdgg04), and Agricultural Science and Technology Tackling Project in Shihezi City of Bashi (2017HZ05).

We thank Elsevier Webshop for assistance with providing language help.

F.Z. and Y.J. are co-first authors.

H.L. and K.Y. are the corresponding authors. E-mail: 1hfeng7227@sohu.com or yukun409@ 163.com.

This is an open access article distributed under the $\mathrm{CC}$ BY-NC-ND license (https://creativecommons.org/ licenses/by-nc-nd/4.0/) fruit quality, and reduce greenhouse gas emissions (Díaz-Pérez et al., 2018; Sharma and Banik, 2014). Tao et al. (2017) proved, through 2 years of research, that the substitution of cow manure and biological fertilizers for chemical fertilizers helps maintain the soil nitrogen level, promote cotton yield, and improve nitrogen use efficiency. With worms as a source of organic fertilizer, together with chemical fertilizers, Kumar et al. (2018) improved the grain quality of rice by increasing the content of trace elements in soil, such as Fe, Mn, and Zn. Cai et al. (2013) found that a combination of compost and chemical fertilizer $(1: 1)$ could improve the nitrogen use efficiency and reduce $\mathrm{N}_{2} \mathrm{O}$ emissions from the soil during corn-wheat rotation. Shen et al. (2017) combined applications of humic acid and NPK fertilizer and found that these fertilizers increased the biomass of flue-cured tobacco by $36.9 \%$, increased the root biomass of the soil layer by 0 to $20 \mathrm{~cm}$, and increased the yield by $12.2 \%$. Zhang et al. (2016) found that replacing 30\% nitrogen fertilizer with compost (cow manure) increased nitrogen absorption, yield, and soil invertase activity, reduced nitrogen loss, and improved soil quality after 3 years of experiments. However, there have been few studies of increasing organic fertilizer and decreasing drip chemical fertilizer in grape production. Therefore, we aimed to study the effects of increasing organic fertilizer and decreasing drip chemical fertilizer on the tree growth and fruit quality of grapes in arid areas during 3 years of experiments to further optimize the integrated technology of drip irrigation with water and fertilizer in production, improve the soil fertility under longterm drip irrigation conditions, and provide a theoretical basis for maintaining the sustainable production of orchards.

\section{Materials and Methods}

Overview of the experimental area

The experiment was performed in the experimental grape orchard (lat. $45^{\circ} 19^{\prime} \mathrm{N}$, long. $86^{\circ} 03^{\prime} \mathrm{E}$ ) of Shihezi Agricultural Science Research Institute in Xinjiang for 3 consecutive years from 2016 to 2018 . The average temperature of the area was between 6.5 and $7.2{ }^{\circ} \mathrm{C}$, the frost-free period was between 168 and $171 \mathrm{~d}$, and the annual number of hours of sunshine was between 2721 and $2818 \mathrm{~h}$. The soil was sandy loam soil with an organic matter content of $31.23 \mathrm{~g} / \mathrm{kg}$, total nitrogen of $135.32 \mathrm{mg} / \mathrm{kg}$, total phosphorus of $89.92 \mathrm{mg} / \mathrm{kg}$, total potassium of $369.56 \mathrm{mg} / \mathrm{kg}$, alkali-hydrolysable nitrogen of $51.11 \mathrm{mg} / \mathrm{kg}$, available phosphorus of $32.95 \mathrm{mg} / \mathrm{kg}$, available potassium of $130.35 \mathrm{mg} / \mathrm{kg}, \mathrm{pH} 8.02$, and conductivity of $0.221 \mathrm{us} / \mathrm{cm}$. compaction, fertility decline, secondary salinization, environmental pollution, premature aging of fruit trees, and poor fruit quality have become increasingly prominent (Luo et al., 2018; Tao et al., 2014). There is an urgent need to further optimize the existing integrated drip irrigation with a water and fertilizer model to improve fruit production.

Characterized by a full nutrient spectrum and their slow release, organic fertilizers can increase the organic matter content in soil and the microbial quantity and activity, improve

\section{Experiment materials and design}

The experiment used the 7-year table grape 'Summer Black' (European and American early-maturing variety). The grape plants were planted in a north-south direction, with a line spacing of $3 \mathrm{~m}$ and a plant spacing of $0.7 \mathrm{~m}$. The grape trellis was a Vshaped scaffold (Fig. 1) placed between the vines. The branches were head-shaped, and 


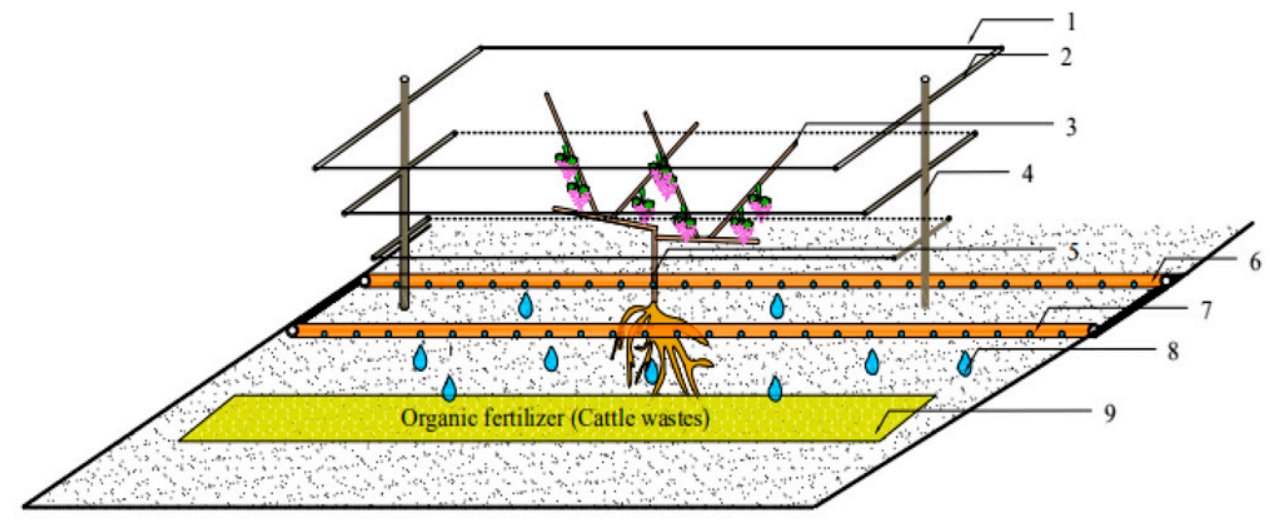

Note:1.Wire 2.Crossbar 3.Fruit branch 4.Column 5.Grapevine 6.Drip tape 8.Water and fertilizer

\section{Organic fertilizer(Cattle wastes)}

Fig. 1. Experimental design.

Table 1. Fertilization scheme.

\begin{tabular}{|c|c|c|c|c|c|c|c|}
\hline \multirow{2}{*}{ Treatment } & \multirow{2}{*}{ Description } & \multirow{2}{*}{\multicolumn{3}{|c|}{$\begin{array}{c}\text { Base fertilizer } \\
\text { Organic fertilizer }\left(\mathrm{kg} / \mathrm{hm}^{2}\right)\end{array}$}} & \multicolumn{3}{|c|}{ Topdressing chemical fertilizer $\left(\mathrm{kg} / \mathrm{hm}^{2}\right)$} \\
\hline & & & & & Urea & $\begin{array}{l}\text { Monoammonium } \\
\text { phosphate }\end{array}$ & $\begin{array}{c}\text { Potassium } \\
\text { sulfate }\end{array}$ \\
\hline$\overline{\mathrm{CK}}$ & No fertilization for 3 consecutive years & 0 & 0 & 0 & 0 & 0 & 0 \\
\hline $\mathrm{T} 1$ & $\begin{array}{l}\text { Organic fertilizer and 1-year reduced } \\
\text { drip fertilizer }\end{array}$ & 0 & 0 & $2,921.4$ & 390.9 & 287.7 & 577.8 \\
\hline $\mathrm{T} 2$ & $\begin{array}{l}\text { Organic fertilizer and } 2 \text { consecutive } \\
\text { years of reduced drip fertilizer }\end{array}$ & 0 & $2,921.4$ & 0 & 390.9 & 287.7 & 577.8 \\
\hline
\end{tabular}

mixed pruning was applied for the medium and short ends. Cement pillars supporting three iron wires were erected every $10 \mathrm{~m}$ along the rows of grapes, and the grape trellis was $\approx 1.5 \mathrm{~m}$ high.

Five treatments were used for the experiment: no fertilizer (CK) for 3 consecutive years; single fertilizer (T0) for 3 consecutive years; organic fertilizer plus 1 year of reducing drip chemical fertilizer (T1); organic fertilizer plus 2 years of reducing drip chemical fertilizer (T2); and organic fertilizer plus 3 years of reducing drip chemical fertilizer (T3). Each treatment was repeated three times for a total of 15 plots, with 7 plants in each plot, and the experimental plots were randomly distributed.

Fermented and decomposed cow manure was used as the source of organic fertilizer with the following nutrient contents: total nitrogen, $2.48 \%$; total phosphorus, $1.79 \%$; and total potassium, $2.50 \%$. In the spring, fermented and decomposed cow manure was applied as base fertilizer $30 \mathrm{~cm}$ from the central trunk of the grape vine and $25 \mathrm{~cm}$ deep (unilateral fertilization on one side of the grape line to avoid mutual influences between the grape plants). The chemical fertilizers (drip application) were urea (N: $46 \%$ ), monoammonium phosphate $(\mathrm{N}: 12 \%$; $\left.\mathrm{P}_{2} \mathrm{O}_{5}: 60 \%\right)$, and potassium sulfate $\left(\mathrm{K}_{2} \mathrm{O}\right.$ : $50 \%$ ) applied during the growing season. The experimental plots were randomly se- lected, and the application amount is shown in Table 1. The integrated device of drip irrigation with water and fertilizer included a water pump, filter, fertilizing tank, switch, and single-wing labyrinth drip irrigation tape. The single-wing labyrinth drip irrigation tape was made by Xinjiang Tianye Co., Ltd. (Xinjiang, China); the inner diameter was $16 \mathrm{~mm}$, the wall thickness was $0.18 \mathrm{~mm}$, the distance between the drippers was $30 \mathrm{~cm}$, the flow rate of the dripper was $2.6 \mathrm{~L} / \mathrm{h}$, and the working pressure was 0.05 to $0.1 \mathrm{Mpa}$. Before dripping, the drip irrigation tape was uniformly placed $30 \mathrm{~cm}$ from both sides of each row of grapes (Fig. 1), and the application of organic fertilizer was exactly below the drip irrigation tape. The drip fertilization time and field management for all five treatments during the growing season were the same as that used for conventional planting.

\section{Testing parameters}

The rhizosphere soil $(20-40 \mathrm{~cm}$ underground) was sampled at 9:00 to 10:00 on day 15 and day 75 after anthesis, and the grape plants and rhizosphere soil were separated for cleaning and drying. Soil organic matter, $\mathrm{pH}$, $\mathrm{EC}$, total nitrogen, available phosphorus, total phosphorus, available potassium, and total potassium content determination were conducted based on the work of Bao (2000).

A Vernier caliper was used to randomly select three bunches of grapes with the same growing potential in each plot, and the top, middle, and bottom grape of each bunch were marked. Beginning from day 15 of anthesis, every 7 -d period was counted as a cycle until the grapes ripened.

The fruit expansion rate for any chosen period is $\mathrm{v}=\left(\mathrm{D}_{2}-\mathrm{D}_{1}\right) / \Delta \mathrm{t}$, where $\mathrm{D}_{1}$ is the longitudinal diameter (transverse diameter) of the grape at the beginning of the chosen period, $\mathrm{D}_{2}$ is the longitudinal diameter (transverse diameter) of the grape at the end of the chosen period, $\Delta t$ is the number of days in the chosen period, and $\mathrm{v}$ is the fruit expansion rate $(\mathrm{mm} / \mathrm{d})$.

Determination of bunch, fruit, and yield. After the grapes ripened fully, three plants in each plot were randomly selected, and the weights of the grape bunches were measured with an electronic balance to calculate the average weight. One fruit was taken from the upper, middle, and lower parts of each bunch, weighed with an electronic balance, and the average fruit weight was calculated.

Measurements of the peel chlorophyll, carotenoids, and anthocyanin content. Grape fruit samples were taken between 9:00 AM and 10:00 AM on days $15,35,55$, and 75 after blossoming (during the earlier and later fruit expansion period, coloring period, and ripening period). The fruit and peel were separated, frozen in liquid nitrogen, and stored at $-80^{\circ} \mathrm{C}$ until tested. The chlorophyll and carotenoid contents of the peel were determined by the 
acetone-ethanol (1:1) mixed extraction method. The absorbance of the filtrate was measured at wavelengths of $663 \mathrm{~nm}, 645 \mathrm{~nm}$, and $440 \mathrm{~nm}$ with an ultraviolet spectrophotometer. The anthocyanin content was measured as described by Liu (2009).

Measurement of the fruit quality. The soluble solids were measured with a PAL-1 saccharimeter (ATAGO, Tokyo, Japan). The titratable acid content was determined by $\mathrm{NaOH}$ titration, the vitamin $\mathrm{C}$ content was determined by 2,6-dichlorophenol indophenol titration, and the total phenol content was determined by the Folin-Ciocalteus method. The contents of total sugar, fructose, sucrose, and glucose were measured as described by Han and Chen (2006).

\section{Data processing and analysis}

Microsoft Excel 2016, Sigmaplot 12.5, and AutoCAD 2007 were used for data processing and plotting. SPSS 19.0 statistical analysis software was used to test the significance of the differences among the growth index, yield, and quality of the 'Summer Black' grapes.

\section{Results}

Effects of increasing organic fertilizer and decreasing drip chemical fertilizer on the soil physicochemical properties

In Fig. 2A, it can be seen that the organic matter content of the soil treated with increasing organic fertilizer and decreasing drip chemical fertilizer (T1, T2, and T3) was significantly higher than that of $\mathrm{CK}$ and T0 $(P<0.05)$. On day 15 after anthesis, the content of organic matter in the rhizosphere soil of T2 was significantly higher than that of the T3 and T1 treatments $(P<0.05)$, but there was no significant difference between $\mathrm{T} 3$ and T1 $(P>0.05)$. On day 75 after anthesis, the content of organic matter in the rhizosphere soil with $\mathrm{T} 1$ was significantly different from that with T2 and T3 $(P<0.05)$; however, there was no significant difference between T2 and T3 $(P>0.05)$.

In Fig. $2 \mathrm{~B}$ and $\mathrm{C}$, it can be seen that the alkali-hydrolyzed nitrogen and available phosphorus contents in the rhizosphere soil of 'Summer Black' grape increased on day 15 and day 75 after anthesis, whereas the other treatments showed a downward trend, and the CK content was the lowest. On day 15 after anthesis, the contents of available nitrogen and phosphorus in the rhizosphere soil of T2 was significantly higher than that in other treatments $(P<0.05)$. On day 75 after anthesis, the content of available nitrogen and phosphorus in the rhizosphere soil of T1 was the highest.

In Fig. 2D, it can be seen that the content of available potassium in the rhizosphere soil of the 'Summer Black' grape increased on day 15 and day 75 after anthesis, except for $\mathrm{CK}$, and the content of available potassium in $\mathrm{CK}$ was the lowest in all treatments. The $\mathrm{pH}$ and conductivity in the rhizosphere soil decreased in all treatments except for CK. On day 75 after anthesis, the soil $\mathrm{pH}$ in $\mathrm{T} 2$ decreased by $1.7 \%$ and $1.5 \%$ compared with
$\mathrm{CK}$ and $\mathrm{T} 0$, and that in $\mathrm{T} 3$ decreased by $1.1 \%$ and $0.9 \%$ compared with CK and T0 (Fig. 2E). Soil conductivity in T2 decreased by $41.2 \%$ and $24.0 \%$ compared with that in $\mathrm{CK}$ and $\mathrm{T} 0$, and soil conductivity in $\mathrm{T} 3$ decreased by $36.8 \%$ and $18.2 \%$ compared with that in CK and $\mathrm{T} 0$, respectively (Fig. 2F).

\section{Effects of increasing organic fertilizer and decreasing fertilization dripping on the growth and development of 'Summer Black' grapes \\ In Table 2, it can be seen that the longitu-} dinal expansion rate of 'Summer Black' grape fruit in this experiment showed a trend of "high-low-high-low," that is, the growth and development of the grape fruit showed a double S-shaped curve. The grape fruit entered the fruit expansion period on day 15 after anthesis, and the fruit reached the highest longitudinal expansion rate during days 15 to 22 after anthesis (the initial stage of expansion), whereas the average rate was as high as $0.64 \mathrm{~mm} / \mathrm{d}$. Then, the rate gradually decreased to its first low point during days 29 to 36 after anthesis, whereas the average rate was 0.14 $\mathrm{mm} / \mathrm{d}$. Then, the fruit longitudinal expansion rate accelerated for the second time, reaching a high point for the second time during days 36 to 43 after anthesis, whereas the average rate was $0.53 \mathrm{~mm} / \mathrm{d}$, which decreased compared with the first high point. With the growth of the 'Summer Black' grapes, the longitudinal expansion rate decreased gradually.

During the first rapid expansion period (days 15-22 after anthesis), the T2 treatment (organic fertilizer and 2 consecutive years of decreasing drip chemical fertilizer) had the largest longitudinal expansion rate $(0.73 \mathrm{~mm} /$ d). The differences among $\mathrm{T} 2$ and $\mathrm{CK}, \mathrm{T} 0$, $\mathrm{T} 1$, and $\mathrm{T} 3$ reached a significant level $(P<$ 0.05). The differences among $\mathrm{CK}, \mathrm{T} 0, \mathrm{~T} 1$, and T3 were not significant $(P>0.05)$. During days 22 to 29 after anthesis, the longitudinal expansion rates of $\mathrm{CK}, \mathrm{T} 0, \mathrm{~T} 1$, and T3 were significantly higher than that of T2 $(P<0.05)$. The first low point occurred from days 29 to 36 after anthesis, and the longitudinal expansion rate of the T2 treatment was the largest $(0.19 \mathrm{~mm} / \mathrm{d})$ and significantly different from that of CK $(P<0.05)$, but the differences among $\mathrm{CK}, \mathrm{T} 0, \mathrm{~T} 1$, and T3 were not significant $(P>0.05)$. During the second rapid expansion period (36-43 d), the longitudinal expansion rate of $\mathrm{T} 1$ was the largest $(0.57 \mathrm{~mm} / \mathrm{d})$, which was significantly higher than that of $\mathrm{CK}, \mathrm{T} 0$, and T2 $(P<$ $0.05)$. From days 43 to 50 after anthesis, the longitudinal expansion rate of $\mathrm{T} 2$ was the largest $(0.36 \mathrm{~mm} / \mathrm{d})$ and significantly higher than that of CK, T0, T1, and T3 $(P<0.05)$. The differences among T0, T1, and T3 were not significant $(P>0.05)$. During the whole process of fruit longitudinal diameter expansion, the average expansion rate was between 0.25 and $0.28 \mathrm{~mm} / \mathrm{d}$, and the differences among different treatments were not significant $(P>0.05)$.

In Table 3, it can be seen that the trend of the transverse expansion rate of the 'Summer Black' grape in the experiment was consis- tent with the longitudinal expansion process, and that the periods of the two fruit expansion peaks were exactly the same. The first transverse diameter expansion peak also appeared during days 15 to 22 after anthesis; then, the expansion rate gradually decreased and reached the first low point from days 29 to 36 after anthesis. The second fruit transverse diameter expansion peak also occurred during days 36 to 43 after anthesis, and it decreased overall compared with the first high point. Then, the transverse expansion rate of the ripe 'Summer Black' grape decreased gradually, that is, the growth and development of the fruit also showed a double S-shaped curve.

During the first rapid expansion period of the fruit transverse diameter (15-22 d after anthesis), the fruit transverse diameter expansion rate of T2 was the largest $(0.72 \mathrm{~mm} / \mathrm{d})$. The differences from $\mathrm{CK}, \mathrm{T} 0, \mathrm{~T} 1$, and $\mathrm{T} 3$ reached a significant level $(P<0.05)$, and the differences among $\mathrm{CK}$ and T0, T1, and T3 were also significant $(P<0.05)$. During days 22 to 29 days after anthesis, the transverse diameter expansion rate of CK was the highest, and it was noticeably higher than that of T0, T1, T2, and T3 $(P<0.05)$. The first low point was reached from days 29 to 36 days after anthesis, and there were no significant differences among treatments $(P>0.05)$. During the second rapid expansion period of the fruit transverse diameter (36-43 d), T2 had the largest transverse diameter expansion rate $(0.56 \mathrm{~mm} / \mathrm{d})$, which was significantly higher than that of $\mathrm{CK}$ and T0 $(P<0.05)$. During the whole process of fruit diameter expansion, the average expansion rate was between 0.23 and $0.26 \mathrm{~mm} /$ $\mathrm{d}$, and the differences among different treatments were not significant $(P>0.05)$.

According to Table 4, during the three postfloral periods (15-22 d, 43-50 d, and 50 $57 \mathrm{~d}$ ), there was a significantly positive correlation between the longitudinal expansion rate and the transverse expansion rate of fruits during the same periods $(P<0.01)$, with the correlation coefficient being highest during the same period. From day 64 to day 71 after anthesis, the longitudinal expansion rate was obviously negatively correlated with the transverse expansion rate during the same period $(P<0.01)$. From day 36 to day 43 after anthesis, the correlation between the two was not significant. This result indicated that the longitudinal growth of the fruit during the second rapid expansion period was not consistent with the transverse growth. Through analysis, the fruit expansion rate of each treatment starting from day 43 after anthesis was always high. During that period, the expansion amounts of 'Summer Black' grapes were $19.41 \mathrm{~mm}$ and $17.91 \mathrm{~mm}$, respectively, with their contribution to the final longitudinal and transverse diameters of the fruit being $82.00 \%$ and $83.50 \%$, respectively.

\section{Effects of increasing organic fertilizer and decreasing fertilizer dripping on the yield}

It can be seen in Table 5 that the magnitude of the longitudinal and transverse diameters of 

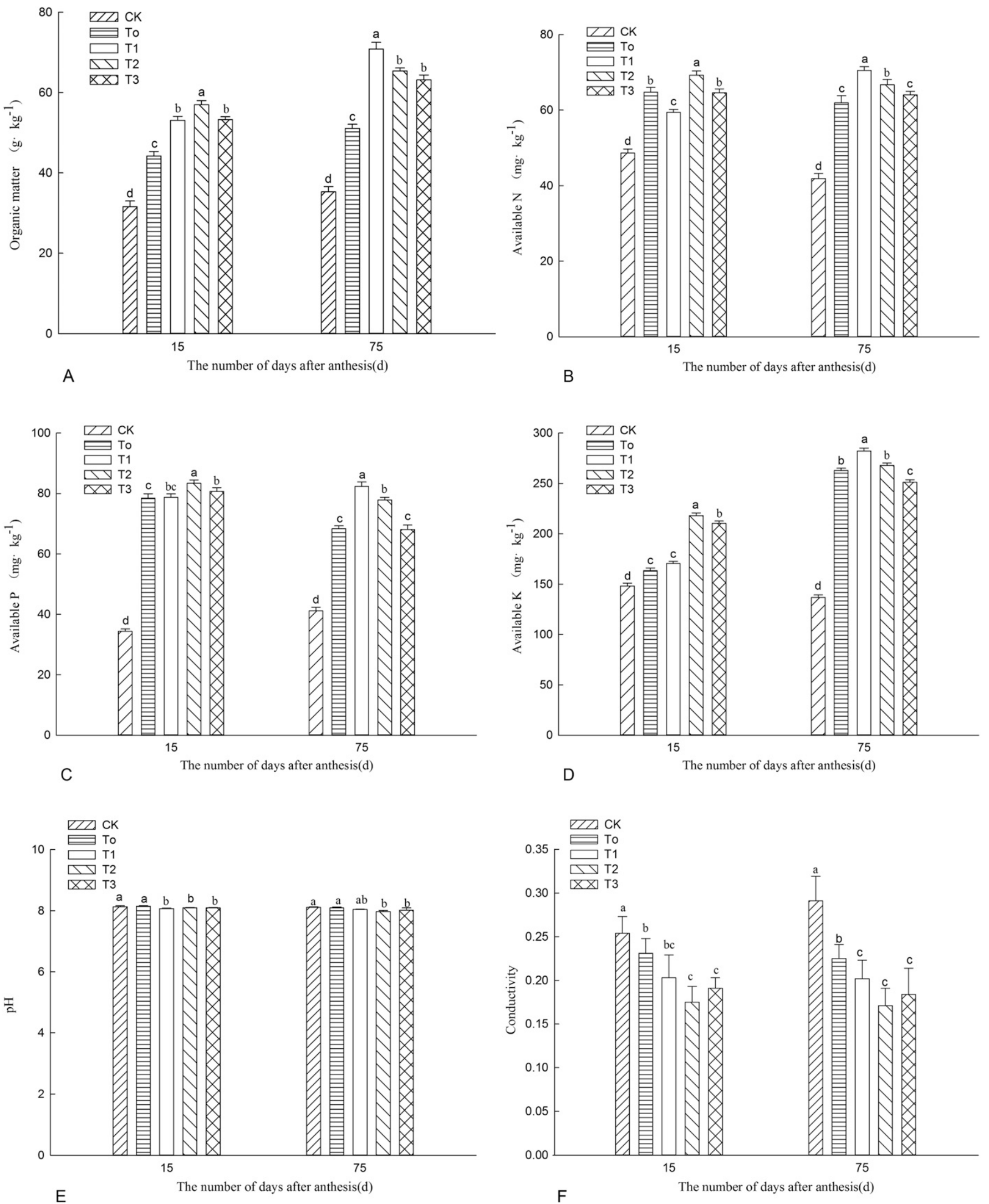

Fig. 2. Organic matter and available N, P, and K contents of rhizosphere soil during different periods. The lowercase letters indicate significant differences $(P<0.05)$.

fruit were in the following order: $\mathrm{T} 2>\mathrm{T} 3>\mathrm{T} 1>$ $\mathrm{T} 0>\mathrm{CK}$; therefore, among these, $\mathrm{T} 2$ was significantly higher than $\mathrm{CK}, \mathrm{T} 0, \mathrm{~T} 1$, and $\mathrm{T} 3$, respectively $(P<0.05)$, but there was no significant difference between $\mathrm{T} 1$ and $\mathrm{T} 2$ regarding the longitudinal expansion. The parameters of individual fruit weight, individual bunch weight, and yield of $\mathrm{T} 2$ were the largest, reaching
$7.06 \mathrm{~g}, 607.1 \mathrm{~g}$, and $30,051.5 \mathrm{~kg} / \mathrm{hm}^{2}$, all of which were higher than that of CK, T0, and T1 $(P<0.05)$. However, the differences between T2 and T3 were not significant. These parameters of 
Table 2. Longitudinal enlargement rate of 'Summer Black' grape under different treatments $\left(\mathrm{mm} \cdot \mathrm{d}^{-1}\right)$.

\begin{tabular}{|c|c|c|c|c|c|c|c|c|c|}
\hline \multirow[b]{2}{*}{ Treatment } & \multicolumn{8}{|c|}{ Number of days after anthesis } & \multirow{2}{*}{$\begin{array}{l}\text { Avg enlargemen } \\
\text { rate }\end{array}$} \\
\hline & $15-22 \mathrm{~d}$ & $22-29 d$ & $29-36 \mathrm{~d}$ & $36-43 \mathrm{~d}$ & $43-50 \mathrm{~d}$ & $50-57 \mathrm{~d}$ & $57-64 \mathrm{~d}$ & $64-71 \mathrm{~d}$ & \\
\hline$\overline{\mathrm{CK}}$ & $0.58 \pm 0.083 \mathrm{~b}$ & $0.24 \pm 0.115 \mathrm{a}$ & $0.09 \pm 0.146 \mathrm{~b}$ & $0.51 \pm 0.048 \mathrm{~b}$ & $0.15 \pm 0.034 \mathrm{c}$ & $0.27 \pm 0.015 \mathrm{a}$ & $0.12 \pm 0.020 \mathrm{~b}$ & $0.05 \pm 0.014 \mathrm{c}$ & $0.25 \pm 0.196 \mathrm{a}$ \\
\hline T0 & $0.63 \pm 0.102 b$ & $0.24 \pm 0.041 \mathrm{a}$ & $0.15 \pm 0.070 \mathrm{ab}$ & $0.52 \pm 0.046 b$ & $0.31 \pm 0.024 \mathrm{~b}$ & $0.11 \pm 0.015 b$ & $0.10 \pm 0.006 \mathrm{c}$ & $0.07 \pm 0.010 \mathrm{~b}$ & $0.27 \pm 0.199 \mathrm{a}$ \\
\hline $\mathrm{T} 1$ & $0.62 \pm 0.041 \mathrm{~b}$ & $0.23 \pm 0.064 \mathrm{a}$ & $0.15 \pm 0.068 \mathrm{ab}$ & $0.57 \pm 0.015 a$ & $0.31 \pm 0.036 \mathrm{~b}$ & $0.10 \pm 0.033 b$ & $0.11 \pm 0.007 \mathrm{bc}$ & $0.09 \pm 0.008 \mathrm{a}$ & $0.27 \pm 0.202 \mathrm{a}$ \\
\hline $\mathrm{T} 2$ & $0.73 \pm 0.015 \mathrm{a}$ & $0.17 \pm 0.028 b$ & $0.19 \pm 0.016 \mathrm{a}$ & $0.53 \pm 0.011 b$ & $0.36 \pm 0.011 \mathrm{a}$ & $0.06 \pm 0.018 \mathrm{c}$ & $0.11 \pm 0.010 \mathrm{bc}$ & $0.08 \pm 0.015 \mathrm{ab}$ & $0.28 \pm 0.227 \mathrm{a}$ \\
\hline T3 & $0.64 \pm 0.016 \mathrm{~b}$ & $0.25 \pm 0.021 \mathrm{a}$ & $0.15 \pm 0.015 \mathrm{ab}$ & $0.54 \pm 0.014 \mathrm{ab}$ & $0.30 \pm 0.011 \mathrm{~b}$ & $0.11 \pm 0.021 \mathrm{~b}$ & $0.13 \pm 0.020 \mathrm{a}$ & $0.06 \pm 0.015 \mathrm{c}$ & $0.27 \pm 0.199 \mathrm{a}$ \\
\hline
\end{tabular}

Data followed by different lowercase letters in a column indicate significant differences $(P<0.05)$.

Table 3. Transverse diameter enlargement rate of 'Summer Black' grape under different treatments $\left(\mathrm{mm} \cdot \mathrm{d}^{-1}\right)$.

\begin{tabular}{|c|c|c|c|c|c|c|c|c|c|}
\hline \multirow[b]{2}{*}{ Treatment } & \multicolumn{8}{|c|}{ Number of days after anthesis } & \multirow{2}{*}{$\begin{array}{c}\text { Avg enlargemen } \\
\text { rate }\end{array}$} \\
\hline & $15-22 \mathrm{~d}$ & $22-29 d$ & $29-36 \mathrm{~d}$ & $36-43 \mathrm{~d}$ & $43-50 \mathrm{~d}$ & $50-57 \mathrm{~d}$ & $57-64 d$ & $64-71 \mathrm{~d}$ & \\
\hline$\overline{\mathrm{CK}}$ & $0.43 \pm 0.167 \mathrm{c}$ & $0.32 \pm 0.108 \mathrm{a}$ & $0.11 \pm 0.079 \mathrm{a}$ & $0.42 \pm 0.020 \mathrm{c}$ & $0.22 \pm 0.010 \mathrm{c}$ & $0.17 \pm 0.013 \mathrm{a}$ & $0.05 \pm 0.016 \mathrm{~d}$ & $0.09 \pm 0.017 \mathrm{a}$ & $0.23 \pm 0.157 \mathrm{a}$ \\
\hline T0 & $0.61 \pm 0.074 \mathrm{~b}$ & $0.22 \pm 0.057 \mathrm{~b}$ & $0.13 \pm 0.071 \mathrm{a}$ & $0.51 \pm 0.038 \mathrm{~b}$ & $0.26 \pm 0.015 b$ & $0.03 \pm 0.014 \mathrm{~d}$ & $0.14 \pm 0.011 b$ & $0.02 \pm 0.011 \mathrm{c}$ & $0.24 \pm 0.207 \mathrm{a}$ \\
\hline $\mathrm{T} 1$ & $0.60 \pm 0.102 b$ & $0.23 \pm 0.090 \mathrm{~b}$ & $0.14 \pm 0.070 \mathrm{a}$ & $0.53 \pm 0.028 \mathrm{ab}$ & $0.26 \pm 0.014 b$ & $0.06 \pm 0.009 \mathrm{c}$ & $0.15 \pm 0.007 \mathrm{~b}$ & $0.02 \pm 0.010 \mathrm{c}$ & $0.25 \pm 0.207 \mathrm{a}$ \\
\hline $\mathrm{T} 2$ & $0.72 \pm 0.012 \mathrm{a}$ & $0.14 \pm 0.016 \mathrm{c}$ & $0.15 \pm 0.014 \mathrm{a}$ & $0.56 \pm 0.034 \mathrm{a}$ & $0.29 \pm 0.024 \mathrm{a}$ & $0.08 \pm 0.020 \mathrm{~b}$ & $0.07 \pm 0.020 \mathrm{c}$ & $0.06 \pm 0.016 b$ & $0.26 \pm 0.235 \mathrm{a}$ \\
\hline $\mathrm{T} 3$ & $0.62 \pm 0.013 \mathrm{~b}$ & $0.22 \pm 0.016 \mathrm{~b}$ & $0.14 \pm 0.012 \mathrm{a}$ & $0.53 \pm 0.150 \mathrm{ab}$ & $0.26 \pm 0.020 \mathrm{~b}$ & $0.07 \pm 0.012 \mathrm{bc}$ & $0.17 \pm 0.014 \mathrm{a}$ & $0.05 \pm 0.023 \mathrm{~b}$ & $0.26 \pm 0.199 \mathrm{a}$ \\
\hline
\end{tabular}

Data followed by different lowercase letters in a column indicate significant differences $(P<0.05)$.

Table 4. Correlation analysis between longitudinal diameter and transverse diameter.

\begin{tabular}{|c|c|c|c|c|c|c|c|c|}
\hline \multirow{2}{*}{$\begin{array}{l}\text { Date for longitudinal } \\
\text { diam measurement }\end{array}$} & \multicolumn{8}{|c|}{ Date for transverse diam measurement } \\
\hline & $15-22 \mathrm{~d}$ & $22-29 d$ & $29-36 \mathrm{~d}$ & $36-43 \mathrm{~d}$ & $43-50 \mathrm{~d}$ & $50-57 \mathrm{~d}$ & $57-64 d$ & $64-71 d$ \\
\hline $15-22 \mathrm{~d}$ & $0.465 * *$ & $-0.493 * *$ & 0.161 & $0.468 *$ & $0.543^{* *}$ & -0.272 & -0.018 & -0.120 \\
\hline $22-29 d$ & 0.002 & 0.110 & -0.060 & -0.241 & -0.192 & 0.027 & 0.247 & -0.109 \\
\hline $29-36 \mathrm{~d}$ & 0.178 & -0.156 & -0.047 & $0.356^{*}$ & 0.286 & $-0.294^{*}$ & 0.086 & -0.121 \\
\hline $36-43 \mathrm{~d}$ & 0.088 & -0.187 & 0.247 & 0.272 & 0.100 & -0.265 & $0.310^{*}$ & $-0.342 *$ \\
\hline $43-50 \mathrm{~d}$ & $0.713 * *$ & $-0.605 * *$ & 0.095 & $0.822 * *$ & $0.659 * *$ & $-0.730 * *$ & $0.437 * *$ & $-0.513 * *$ \\
\hline $50-57 \mathrm{~d}$ & $-0.670 * *$ & $0.655 * *$ & -0.135 & $-0.851 * *$ & $-0.702 * *$ & $0.759 * *$ & $-0.443 * *$ & $0.542 * *$ \\
\hline $57-64 d$ & -0.091 & 0.092 & -0.129 & 0.010 & -0.008 & 0.216 & 0.067 & 0.256 \\
\hline $64-71 \mathrm{~d}$ & $0.343 *$ & $-0.369 * *$ & 0.102 & $0.494 * *$ & $0.323 *$ & $-0.492 * *$ & 0.285 & $-0.531 * *$ \\
\hline
\end{tabular}

*, **Significant correlations at $P<0.05$ or 0.01 , respectively.

Table 5. Yield of 'Summer Black' grape under different treatments.

\begin{tabular}{|c|c|c|c|c|c|}
\hline Treatment & Longitudinal diam (mm) & Transverse diam (mm) & Berry wt (g) & Bunch wt (g) & Yield $\left(\mathrm{kg} / \mathrm{hm}^{2}\right)$ \\
\hline$\overline{\mathrm{CK}}$ & $22.34 \pm 0.561 \mathrm{~d}$ & $19.84 \pm 0.572 \mathrm{e}$ & $5.37 \pm 0.265 \mathrm{c}$ & $546.1 \pm 11.75 \mathrm{c}$ & $27,032.0 \pm 38.77 \mathrm{c}$ \\
\hline T0 & $23.66 \pm 0.249 \mathrm{c}$ & $21.25 \pm 0.544 \mathrm{~d}$ & $6.16 \pm 0.254 b$ & $579.5 \pm 9.81 \mathrm{~b}$ & $28,685.3 \pm 32.39 \mathrm{~b}$ \\
\hline $\mathrm{T} 1$ & $23.89 \pm 0.442 b$ & $21.60 \pm 0.352 \mathrm{c}$ & $6.17 \pm 0.211 \mathrm{~b}$ & $573.8 \pm 6.13 b$ & $28,403.1 \pm 20.27 b$ \\
\hline $\mathrm{T} 2$ & $24.35 \pm 0.512 \mathrm{a}$ & $22.41 \pm 0.377 \mathrm{a}$ & $7.06 \pm 0.124 \mathrm{a}$ & $607.1 \pm 7.09 \mathrm{a}$ & $30,051.5 \pm 23.39 \mathrm{a}$ \\
\hline $\mathrm{T} 3$ & $23.95 \pm 0.501 \mathrm{~b}$ & $22.15 \pm 0.436 \mathrm{~b}$ & $6.89 \pm 0.173 \mathrm{a}$ & $602.1 \pm 6.65 \mathrm{a}$ & $29,802.3 \pm 21.97 \mathrm{a}$ \\
\hline
\end{tabular}

Data followed by different lowercase letters in a column indicate significant differences $(P<0.05)$.

T0 and T1 were all remarkably higher than those of CK $(P<0.05)$, but no significant difference was present between $\mathrm{T} 0$ and $\mathrm{T} 1$ $(P>0.05)$.

\section{Effect of increasing organic fertilizer and decreasing fertilizer dripping on grape coloring}

Figure 3 showed that the chlorophyll in the grapes decreased gradually as the grapes ripened, and it decreased rapidly from days 55 to 75 after anthesis. However, during the same period of time, the anthocyanin accumulated quickly. Regarding the carotenoid, there was little change, but it increased slightly. The chlorophyll content of T2 was significantly lower than that of $\mathrm{CK}, \mathrm{T} 0$, and T1 $(P<0.05)$, whereas T2 and T3 exhibited no significant difference $(P>0.05)$. From days 55 to 75 after anthesis, the anthocyanin content of T2 was significantly higher than that of $\mathrm{CK}$, T0, and T1 $(P<0.05)$, with an increase of $28.0 \%, 21.3 \%, 22.6 \%, 9.8 \%$, $33.3 \%, 22.1 \%$, and $20.9 \%$, respectively. However, there was no dramatic difference between T2 and T3 $(P>0.05)$. From days 55 to 75 after anthesis, the carotenoid content of $\mathrm{T} 2$ was significantly higher than that of $\mathrm{CK}$, T0, and T1, respectively $(P<0.05)$.

\section{Effect of increasing organic fertilizer and decreasing fertilizer dripping on grape quality}

As seen in Table 6, the soluble solids and sugar acid ratio of $\mathrm{T} 2$ were significantly higher than that of CK, T0, T1, and T3, respectively $(P<0.05)$, and they were $5.4 \%$ and $18.4 \%$ higher than T0 (one application of fertilizer). The titratable acid of T2 was significantly lower than that of CK, T0, and T1 $(P<0.05)$, and it was $11.0 \%$ lower than T0.

In terms of nutritional value, the vitamin $\mathrm{C}$ content of T2 was the highest $(3.936 \mathrm{mg} / 100$ $\mathrm{g})$, and it was significantly higher than that of CK, T0, and T1 $(P<0.05)$ and $6.9 \%$ higher than T0. However, there was no significant difference between T2 and T3 $(P>0.05)$. The total phenol content of $\mathrm{T} 2$ was significantly higher than that of CK, T0, and T1 $(P<0.05)$, and it was $15.8 \%$ higher than T0.
The content of sugars in grapes had the following order: total sugar $>$ fructose $>$ glucose $>$ sucrose; the average sucrose content was the lowest, being just $1.29 \%$. The total sugar content of T2 was significantly higher than that of CK, T0, and T1 $(P<0.05)$, and it was $4.8 \%$ higher than $\mathrm{T} 0$. The fructose content of $\mathrm{T} 2$ was significantly higher than that of CK, T0, T1, and T3 $(P<0.05)$, and it was $5.4 \%$ higher than T0. The sucrose content of T2 was remarkably higher than that of CK, T0, T1, and T3 $(P<0.05)$, and it was $5.4 \%$ higher than $\mathrm{T} 0$. The glucose content of $\mathrm{T} 2$ was significantly higher than that of $\mathrm{CK}$, T0, and T1 $(P<0.05)$, and it was $4.4 \%$ higher than T0, but there was no remarkable difference between T2 and T3 $(P>0.05)$.

\section{Correlation analysis between the soil fertility and fruit quality of the 'Summer Black' grape}

Table 7 showed that $\mathrm{pH}$ was positively correlated with titratable acid $(P<0.01)$ and negatively correlated with the sugar-acid ratio, anthocyanin, total sugar, $\mathrm{Vc}$, and phenol 

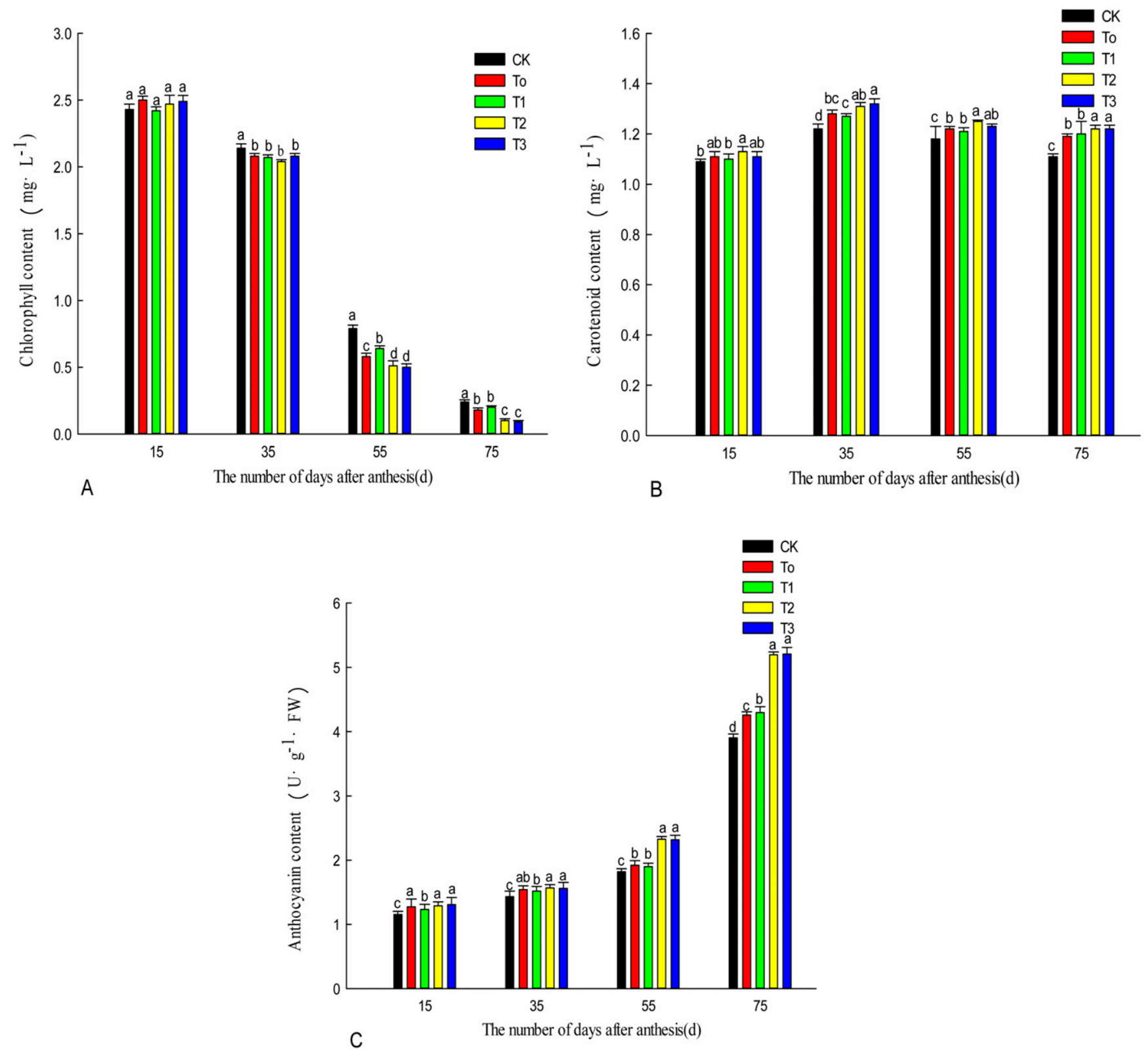

Fig. 3. Chlorophyll, carotenoid, and anthocyanin contents of grape peel during different periods. The data are the mean ( \pm SE) of five replicates, and different lowercase letters indicate significant differences $(P<0.05)$.

$(P<0.01)$. EC showed a very significant positive correlation with titratable acid $(P<0.01)$ and negative correlations with soluble solids and the sugar-acid ratio $(P<0.01)$. There was a significant positive correlation among organic matter, available $\mathrm{K}$, and soluble solids $(P<$ $0.05)$, a significant positive correlation with the sugar-acid ratio, anthocyanin, total sugar, Vc, and total phenol $(P<0.01)$, and a significant negative correlation with titratable acid $(P<$ $0.01)$. There was a significant positive correlation between the alkali-hydrolyzed nitrogen and gluconic acid ratio $(P<0.05)$. Furthermore, there was a significant positive correlation with soluble solids $(P<0.05)$, which was negatively correlated with titratable acid $(P<0.01)$. The available phosphorus was positively correlated with soluble solids $(P<0.05)$ and negatively correlated with titratable acid $(P<0.01)$.

\section{Discussion}

It has been realized that increasing organic amendments and decreasing the application of inorganic fertilizers can optimize soil microorganisms, thus promoting the internal circulation of soil microenvironment nutrients (Germaine, et al., 2010). Because of its slow release of nutrients, high efficiency and utilization of fertilizers, and low environmental pollution, it has become a new and popular fertilizer approach in China. Zhao et al. (2016), in a study of a rice-wheat twoseason (rice-wheat) cropping system, found that pig manure organic-inorganic compound weight reduction can improve the utilization rate of soil nutrients, improve soil fertility, and form a stable and sustainable cycle. Sharma et al. (2017) showed that 25 $\mathrm{kg} /$ plant vermi-compost (VC), $40 \mathrm{~g} / \mathrm{plant}$ biofertilizer (BF), $30 \mathrm{~kg} /$ plant farmyard manure (FYM), vermi-wash (VW) 1:10, and cow urine $(\mathrm{CU})$ 1:10 VC treatments significantly improved the soil physical and chemical properties, neutralized the soil acidity and alkalinity, and increased the soil waterholding capacity and soil organic matter content. This study showed that the soil $\mathrm{pH}$ and EC values decreased with the increase of grape maturity on days 15 and 75 after anthesis. The soil $\mathrm{pH}$ and $\mathrm{EC}$ of organic fertilizer and decreasing drip chemical fertilizer treatments (T1, T2, and T3) were lower than those of single fertilizer treatment (T0) and $\mathrm{CK}$, which tended to make the soil acidic-alkali environment neutral. This phenomenon may be due to the production of soil organic acids (oxalic acid, acetic acid, glutamic acid) and the increase of soil organic matter content (Srikant, et al., 2000), thus 


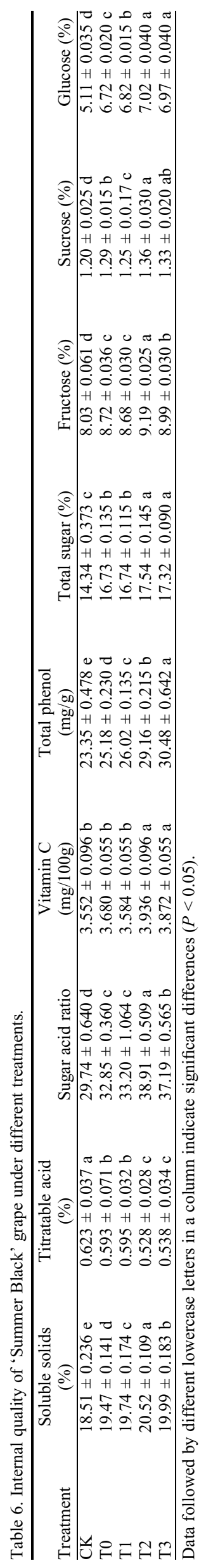

improving the soil structure. The results showed that with the increase of grape maturity ( $15 \mathrm{~d}$ after anthesis and $75 \mathrm{~d}$ after anthesis), the contents of soil organic matter, alkali-hydrolyzed nitrogen, available phosphorus, and available potassium increased in all fertilization treatments. At $15 \mathrm{~d}$ after anthesis, the indexes of the T2 and T3 treatments were higher than those of $\mathrm{T} 0$, and the organic matter of the $\mathrm{T} 1$ soil was significantly higher than that of $\mathrm{T} 0$, whereas the other indexes exhibited no significant difference. At $75 \mathrm{~d}$ after anthesis, the soil organic matter of the T3 treatment was significantly higher than that of $\mathrm{T} 0$, and the other indicators were not significantly different from that of T0 treatment. This phenomenon may be because the application of organic fertilizer increased the mineralization of nitrogen and the existence of microorganisms, such as N2fixing bacteria (Sharma et al., 2017), which made them accumulate in the form of available nitrogen. Organic fertilizer can significantly increase the available phosphorus content in soil by releasing various organic acid insoluble organic phosphorus components and change the balance between forms of potassium to form soluble potassium in soil from relatively exchangeable potassium, thus increasing the content of available potassium.

The nutritional characteristics and selective absorption by grapes can easily result in preferential absorption of certain nutrients. Because grape vines are a perennial plant, their growth in a fixed region is likely to cause uneven nutrient contents in the soil, which can be alleviated by the use of organic fertilizers ( $\mathrm{Li}$ et al., 2010; Lin et al., 1994; Marinari et al., 2007). The results of the current experiment showed that the longitudinal and transverse diameter expansion rates of T1 and T2 were higher than that of T0 at the beginning of expansion. In the middle and later periods, the expansion rate decreased, and the transverse expansion rate decreased significantly. The S-shaped "fast-slow-fastslow" growth and development process of 'Summer Black' grape during the fruit enlargement process was consistent with the results of the study by Zhang et al. (2014). Compared with T0, the T2 treatment had an obvious effect on the growth of the grape fruits in the two expansions, with the individual fruit weight, single bunch weight, and yield increasing by $14.6 \%, 4.8 \%$, and $4.7 \%$, respectively. The effect of the T3 treatment was not as significant as that of the T2 treatment, and the $\mathrm{T} 1$ treatment had no obvious effect. The results showed that with the increase in organic fertilizer and the number of years of fertilizer dripping, the effect on the growth and yield of 'Summer Black' grape was the best in the second year, and the effect in the third year was reduced. This observation might be because the time sensitivity of organic fertilizers led to a decrease of fertilizer efficiency in the third year.

Peel coloring is affected by a variety of pigments. The coloring of grape fruit is mainly due to the biosynthesis and accumulation of anthocyanin, whereas its expression is limited by the interference of chlorophyll and carotenoid in the peel (Liu et al., 2009). The research results of Al-Ismaily et al. (2014) under saline water irrigation conditions were consistent - a combination of organic fertilizer and chemical fertilizer significantly increased the yellowness of tomato fruit, thereby improving its color quality. The results showed that the chlorophyll of 'Summer Black' grape peel rapidly decomposed, and the anthocyanin of the peel was rapidly synthesized during the period from fruit coloring to ripeness. The anthocyanin content in the grape peel of T2 increased by $21.3 \%$ and $22.0 \%$ compared with that of $\mathrm{T} 0$, and the chlorophyll degradation was accelerated. Carotenoids increased slightly throughout the whole grape growth cycle, thus promoting the early coloring and ripening of the grape fruit.

Sugar and its activated forms provide a series of raw materials, such as substrate, energy, and intermediate reactants, for various metabolic processes of fruits, which have an important role in the fruit quality and flavor (Velasco et al., 2010). A large number of studies have shown that the combination of organic fertilizer and chemical fertilizer improved the quality of peach (Sharma et al., 2017), potatoes (Illera-Vives et al., 2017), and others. According to the current experimental study, the soluble solid content, sugar acid ratio, vitamin $\mathrm{C}$, and total phenol content of T2-treated 'Summer Black' grape increased significantly, and these values were $5.4 \%, 18.4 \%, 6.9 \%$, and $15.8 \%$ higher than T0, respectively. The analysis of the sugar content also showed that the total sugar, fructose, sucrose, and glucose content of grape fruit resulting from organic fertilizer and 2 years of decreasing fertilizer dripping were significantly increased. This result was probably due to the increase of organic matter content in the soil and various bioactive substances through the application of organic fertilizer, which improved the soil physical and chemical properties, accelerated the accumulation of photosynthates, promoted the conversion of acid to sugar in the grape fruit, and increased the soluble solid content, thereby improving the quality of the 'Summer Black' grapes.

After a 3-year test in a targeted region, the results showed that the $\mathrm{T} 2$ and $\mathrm{T} 3$ treatments were obviously better than the $\mathrm{CK}, \mathrm{T} 0$, and $\mathrm{T} 1$ treatments. The minor difference between $\mathrm{T} 0$ and $\mathrm{T} 1$ indicated that there were significant differences in fruit growth and grape fruit quality with the increase of organic fertilizer and the decrease of chemical fertilizer in different years. Nevertheless, because grapes are perennial fruits, and because organic fertilizer is a long-term source, the inherent mechanism of increasing organic fertilizers and decreasing chemical fertilizers, especially the transformation of organic carbon and organic nitrogen of soil, the response of grape roots to different nitrogen sources, and the changes of the grape rhizosphere environment need to be further studied from a more micro-perspective. 


\begin{tabular}{|c|c|c|c|c|c|c|c|}
\hline \multirow[b]{2}{*}{ Soil fertility factor } & \multicolumn{7}{|c|}{ Fruit quality index } \\
\hline & Soluble solids & Titratable acid & Sugar acid ratio & Anthocyanin & Total sugar & Vitamin C & Total phenol \\
\hline $\mathrm{PH}$ & -0.209 & $0.696^{* *}$ & $-0.763^{* *}$ & $-0.640^{* *}$ & $-0.672^{* *}$ & $-0.660 * *$ & $-0.712 * *$ \\
\hline $\mathrm{EC}$ & $-0.492 * *$ & $0.667 * *$ & $-0.463^{* *}$ & -0.243 & -0.135 & -0.171 & -0.321 \\
\hline Organic matter & $0.450^{*}$ & $-0.801 * *$ & $0.708^{* *}$ & $0.618^{* *}$ & $0.507 * *$ & $0.489 * *$ & $0.575 * *$ \\
\hline Available N & $0.611 * *$ & $-0.666^{* *}$ & $0.431 *$ & 0.293 & 0.135 & 0.139 & 0.254 \\
\hline Available P & $0.665^{*}$ & $-0.443 * *$ & 0.246 & 0.208 & 0.017 & 0.010 & 0.140 \\
\hline Available K & $0.431 *$ & $-0.865 * *$ & $0.794 * *$ & $0.767 * *$ & $0.681 * *$ & $0.669 * *$ & $0.695 * *$ \\
\hline
\end{tabular}

$*, * *$ Significant correlations at $P<0.05$ or 0.01 , respectively.

\section{Conclusion}

The results showed that increasing organic fertilizer and decreasing drip chemical fertilizer application can increase the content of soil organic matter, alkali-hydrolyzed nitrogen, available $\mathrm{P}$ and $\mathrm{K}$, and $\mathrm{EC}$. The effect of increasing organic fertilizer and decreasing chemical fertilizer for 2 years on soil fertility was obvious. In some indexes, there was no significant difference between decreasing chemical fertilizer for 1 year and for 3 years.

Organic fertilizer and 2 years of decreasing drip chemical fertilizer can significantly promote the growth of the 'Summer Black' grape (in the longitudinal and transverse diameters), increase single fruit weight, bunch weight, the grape harvest, fruit coloring, and early ripeness, and improve the grape fruit quality (sugar content, sugar acid ratio, vitamin $\mathrm{C}$, total phenol). Organic fertilizer plus 3 years of decreasing drip chemical fertilizer also had beneficial effects, but they were not significant. There was no significant difference between organic fertilizer and 1 year of decreasing fertilizer dripping and the application of chemical fertilizer alone.

\section{Literature Cited}

Al-Ismaily, S.S., R.A. Al-Yahyai, and S.A. AlRawahy. 2014. Mixed fertilizer can improve fruit yield and quality of field-grown tomatoes irrigated with saline water. J. Plant Nutr. 37(12): 1981-1996.

Bao, S.D. 2000. Soil and agricultural chemistry analysis. 3rd ed. Beijing: China Agriculture Press.

Cai, Y., W. Ding, and J. Luo. 2013. Nitrous oxide emissions from Chinese maize-wheat rotation systems: A 3-year field measurement. Atmos. Environ. 65(65):112-122.

Díaz-Pérez, J.C., J. Bautista, G. Gunawan, A. Bateman, and C.M. Riner. 2018. Sweet onion (Allium cepa L.) as influenced by organic fertilization rate: 2 . Bulb yield and quality before and after storage. Amer. Soc. Hort. Sci. 53(4):459-464.

Germaine, K.J., S. Chhabra, B. Song, D. Brazil, and D.N. Dowling. 2010. Microbes and sustainable production of biofuel crops: A nitrogen perspective. Biofuels 1(6):877-888.

Han Z.H. and Chen K.S. 2006. Experimental Horticulture. Higher Education Press 389-392 (in Chinese).

Huang B.X., 2017. China rural statistics yearbook. China Statistics Publishing House. (in Chinese).

Illera-Vives, M., S.S. Labandeira, L.I. Loureiro, and M.E. López-mosquera. 2017. Agronomic assessment of a compost consisting of seaweed and fish waste as an organic fertilizer for organic potato crops. J. Appl. Phycol. 29(3):16631671.

Kumar, K.A., D.K. Swain, and P.B.S. Bhadoria. 2018. Split application of organic nutrient improved productivity, nutritional quality and economics of rice-chickpea cropping system in lateritic soil. Field Crops Res. 223:125-136.

Li, J.S., Li, Y.F., Wang, J., Wang, Z., and Zhao, J.X., 2016. Microirrigation in China: history, current situation and prospects. J. Hydraul. Eng. 47(3):372-381 (in Chinese).

Li, Z.F., M.G. Xu, H.M. Zhang, S.X. Zhang, and W.J. Zhang. 2010. Sustainability of crop yield in China under long-term fertilization and different ecological conditions. Chin. J. Appl. Ecol. 21(5):1264-1269. (in Chinese).

Lin, B., J.W. Lin, and J.K. Li. 1994. The changes of crop yield and soil fertility with long-term fertilizer application [J]. J. Plant Nutr. Fertil. 1(1):6-18. (in Chinese)

Liu, X.J., C.B. Feng, S.Q. Feng, H.B. Wang, J. Shi, N. Wang, W.Y. Chen, and X.S. Chen. 2009 Studies on anthocyan in biosynthesis and activities of related enzymes of 'Ralls' and its bud mutation. Acta Hort. Sin. 36(9):1249-1254. (in Chinese).

Luo, T., J.H. Li, R. Hua, Z.C. Luo, and L.Y. Chen. 2018. Effects of organic fertilizer extract on soil nutrient activation and use efficiency in cotton field. J. Plant Nutr. Fertil. 24(5):12551265. (in Chinese).

Marinari, S., G. Masciandaro, B. Ceccanti, and S. Grego. 2007. Evolution of soil organic matter changes using pyrolysis and metabolic indices: A comparison between organic and mineral fertilization. Bioresour. Technol. 98(13):24952502.

Sharma, R.C. and P. Banik. 2014. Vermicompost and fertilizer application: Effect on productivity and profitability of baby corn (Zea Mays L.) and soil health. Compost Sci. Util. 22(2):8392.

Sharma, S., D.S. Sharma, and P. Kumar. 2017. Response of nectarines to organic fertilization under the rain-fed ecosystem of Northwest Himalayas. J. Plant Nutr. 40(3):2014-2025.

Shen, H., Z.J. Shen, Y. Li, Y.L. Lai, Z.H. Jia, and J.H. Yi. 2017. Promotion of lateral root growth and leaf quality of flue-cured tobacco by the combined application of humic acids and NPK chemical fertilizers. Exp. Agr. 53(1):1-12.

Srikant, K., C.A. Srinivasamurthy, A. Siddaramappa, and R.A.R. Parama. 2000. Direct and residual effect of enriched composts, FYM, vermicompost and fertilizers on properties of an alfisols. J. Indian Soc. Soil Sci. 48(3):496499.

Tao, R., R. Li, L. Tan, and G.X. Chu. 2014. Effects of application of different organic manures with chemical fertilizer on cotton yield, $\mathrm{N}$ and $\mathrm{P}$ utilization efficiency under drip irrigation. Cotton Sci. 26(4):342-349. (in Chinese).

Tao, R., S.A. Wakelin, Y. Liang, and G.X. Chu. 2017. Organic fertilization enhances cotton productivity, nitrogen use efficiency, and soil nitrogen fertility under drip irrigated field. Agron. J. 109(6):2889-2897.

Velasco, R., A. Zharkikh, and J. Affourtit, et al. 2010. The genome of the domesticated apple (Malus $\times$ domestica Borkh.). Nat. Genet. 42(10): 833-839.

Zhao, J., T. Ni, J. Li, Q. Lu, Z.Y. Fang, Q.W. Huang, R.F. Zhang, R. Li, B. Shen, and Q.R. Shen. 2016. Effects of organic-inorganic compound fertilizer with reduced chemical fertilizer application on crop yields, soil biological activity and bacterial community structure in a rice-wheat cropping system. Appl. Soil Ecol. 99(18):1-12.

Zhang, Y., Z.Y. Cheng, W.T. Wang, Y.X. Wu, L.L. Niu, X.X. Zhang, Y. Gao, N.N. Chen, and Q.M. Ma. 2014. Effect of water stress in different growth stages on grape yield and fruit quality under delayed cultivation facility. Trans. Chin. Soc. Agricul. Eng. 30(24):105-113. (in Chinese).

Zhang, Y.L., C.H. Li, Y.M. Wang, H.M. Hu, P. Christie, and J.L. Zhang. 2016. Maize yield and soil fertility with combined use of compost and inorganic fertilizers on a calcareous soil on the North China Plain. Soil Tillage Res. 155:8594. 